\section{Progress in the past century and future of eye care}

\author{
Gullapalli N Rao
}

Since the first issue of British Journal of Ophthalmology a century ago, the progress in controlling blindness and visual impairment globally has been impressive. Transformative outcomes of eye research, innovative ways of eye care delivery, rapid dissemination of knowledge (in which $B J O$ has played a major role) and the true spirit of partnership have made this possible. While the initial benefits were largely limited to the population of more advanced economies, in the past two to three decades, increasingly visible impact is made in the low/middle-income countries. The pace is now accelerating and the coverage more widespread. Advances in communication and information technology are changing the landscape of healthcare.

Globally, 'Universal Health Coverage' has become an oft-repeated slogan from the richest to the poorest of the nations. Whether this aspiration can ever be realised is largely dependent on the increasing availability and optimal utilisation of resources (human and financial). ${ }^{1}$ In the field of eye care, successful models exist and large-scale replication of these models offer a way forward.

Multisectoral collaborations, publicprivate partnerships and global partnerships have all played a pivotal role in this phenomenon. Elimination of blindness from onchocerciasis and trachoma seems imminent, with the programmes that made this possible due to become big public health success stories. ${ }^{2}{ }^{3}$ The burden of cataract blindness remains a huge challenge but efficient and costeffective interventions to control this problem are already available. The example of India offers all the essential ingredients of a successful formula. Government commitment leading to scaling up of infrastructure, training programmes and subsidies for surgery coupled with the philanthropic spirit of ophthalmologists and local production of

Correspondence to Dr Gullapalli N Rao, LV Prasad Eye Institute, L V Prasad Marg, Road \# 2, Hyderabad 500034, India; gnrao@lvpei.org equipment and consumables were behind this success. With some local modifications, this example may help the other parts of the world too.

Reliable information on the magnitude of blindness and visual impairment, success of global programmes such as VISION 2020: The Right to Sight, successful advocacy efforts that led to favourable World Health Assembly resolutions giving prioritisation for prevention of blindness are the contributing factors for the success. ${ }^{4}$

While the results achieved through targeting certain diseases have been impressive, the emerging challenges of glaucoma, age-related macular degeneration, diabetic retinopathy, corneal blindness, childhood blindness and low vision problems warrant a more comprehensive approach to eye care. Currently, a significant proportion of these problems are dealt with at the tertiary care level limiting access, availability and affordability. Large-scale public health approaches in tackling these problems still remain elusive. Integrated, multi-level models of comprehensive eye care delivery (from primary to advanced tertiary levels of care), addressing all causes of blindness are to be replicated on a large scale with appropriate modifications where necessary. ${ }^{5}$

The problem of uncorrected refractive errors (URE) has been neglected for a long while. While cataract is the most common cause of blindness, it is now evident that URE contributes to half of the burden of visual impairment globally. This is fraught with challenges of service delivery, affordability, spectacle supply chains and trained human resources. Vision centres, mobile refraction units, social entrepreneurship models and application of mobile telephones are all being tried. While we have low-cost correction available, widespread application is the challenge.

Availability of appropriately trained human resources is a major constraint in many parts of the world. More and better education programmes for all cadres of eye care personnel are required. The spirit of global collaboration in this arena is laudable and the increasing number of centres of excellence in education and research evolving in low/middle-income countries augurs well for the future of eye care. The significance of eye care team approach is also scaling greater significance.

High-quality research, however, still remains largely a preserve of the developed countries. Recent initiatives by many international organisations to build and enhance the research capacity in low/ middle-income countries are a positive development. The inculcation of the spirit of enquiry will have a salutary effect on the quality of care and education in the low/middle-income countries.

As we look into the future, the breathtaking revolution in technology is shrinking the world and bringing it closer. Digital technology and disruption of technology will have a major influence on the way we provide eye care in the future. Here again, eye care is leading the way. The present state of ophthalmology is largely due to the strong foundation laid by our ophthalmic forefathers over generations, whose legacy we are continuing. The British Journal of Ophthalmology has proved to be an effective vehicle for enhancing the knowledge globally over the past 100 years.

\section{Competing interests None declared.}

Provenance and peer review Commissioned; internally peer reviewed.

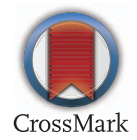

To cite Rao GN. Br J Ophthalmol 2016;100:2.

Br J Ophthalmol 2016;100:2

doi:10.1136/bjophthalmol-2015-308162

\section{REFERENCES}

1 Ooms G, Latif LA, Waris $A$, et al. Is universal health coverage the practical expression of the right to health care? BMC Int Health Hum Rights 2014;14:3.

2 Hopkins AD. From 'control to elimination': a strategic change to win the end game. Int Health 2015:7:304-5.

3 Mpyet C, Kello AB, Solomon AW. Global elimination of trachoma by 2020: a work in progress. Ophthalmic Epidemiol 2015;22:148-50.

4 [No authors listed]. The resolution of the world health assembly on the elimination of avoidable blindness. Community Eye Health 2003;16:18.

5 Qureshi BM, Mansur R, Al-Rajhi A, et al. Best practice eye care models. Indian J Ophthalmol 2012;60:351-7. 